\title{
Distinguishing colour variants of Serapias perez-chiscanoi (Orchidaceae) from related taxa on the Iberian Peninsula
}

\author{
by \\ Caspar Venhuis ${ }^{1} \&$ J. Gerard B. Oostermeijer ${ }^{2}$ \\ ${ }^{1}$ Derde Goudsbloemdwarsstraat 21,1015 KA Amsterdam, The Netherlands. casvenhuis@gmail.com \\ ${ }^{2}$ Institute for Biodiversity and Ecosystem Dynamics (IBED), Universiteit van Amsterdam, Science Park 904 , \\ 1098 XH Amsterdam, The Netherlands. j.g.b.oostermeijer@uva.nl
}

\begin{abstract}
Venhuis, C. \& Oostermeijer, J.G.B. 2011. Distinguishing colour variants of Serapias perez-chiscanoi (Orchidaceae) from related taxa on the Iberian Peninsula. Anales Jard. Bot. Madrid 68(1): 49-59.

Serapias perez-chiscanoi has a stable and uniform appearance with green flowers. Throughout its distribution area, however, plants have been found with deviant pink to red flowers that show similarities with other taxa that are occasionally pale flowered. S. perez-chiscanoi is easy to differentiate from S. cordigera subsp. cordigera by the colour of the flowers (S. cordigera subsp. cordigera has red to purple flowers) and the fact that the hypochile dimensions of $S$. perez-chiscanoi are significantly smaller. It is, however, more difficult to distinguish it from individuals of $S$. cordigera subsp. gentilii with pale flowers, which occur frequently. The two taxa differ in colour pattern and floral dimensions, especially the hypochile length, which is shorter in S. perez-chiscanoi. Pale-flowered individuals of another species, S. parviflora, are easily distinguished by their significantly smaller flowers. S. perez-chiscanoi occurs in Spain in the autonomous regions of Extremadura and Castilla-La Mancha and in Portugal, S. cordigera subsp. gentilii seems to occur along the coastal regions of SW Portugal, while S. cordigera subsp. cordigera and S. parviflora are distributed throughout the Iberian Peninsula.
\end{abstract}

Keywords: Orchidaceae, Serapias perez-chiscanoi, Serapias cordigera subsp. gentilii, flower colour, floral dimensions, Spain, Portugal.

\section{Resumen}

Venhuis, C. \& Oostermeijer, J.G.B. 2011. Distinción de variantes en color de Serapias perez-chiscanoi (Orchidaceae) en relación con táxones de la Península Ibérica. Anales Jard. Bot. Madrid 68(1): 49-59 (en inglés).

La Serapias perez-chiscanoi tiene una apariencia estable y uniforme con flores verdes. Sin embargo, a lo largo de su área de distribución, se han encontrado ejemplares de flores con coloraciones desviantes de color rosa hasta rojo que muestran similitudes con otros táxones que presentan ocasionalmente flores pálidas. Serapias perez-chiscanoi es fácil de diferenciar con respecto a $S$. cordigera subsp. cordigera por el color de las flores (S. cordigera subsp. cordigera tiene flores de rojizas hasta púrpura) y por las dimensiones significativamente más pequeñas del hipoquilo de S. perez-chiscanoi. Sin embargo es más difícil hacer una distinción con respecto a S. cordigera subsp. gentilii, ya que los individuos de este taxon presentan flores pálidas, lo que ocurre con frecuencia. Estos dos táxones se diferencian por el patrón de colores y por las pequeñas dimensiones de las piezas florales, especialmente el tamaño del hipoquilo más corto en S. perez-chiscanoi. Los individuos de flores pálidas de S. parviflora se pueden distinguir fácilmente gracias a sus flores de pequeño tamaño. Serapias perez-chiscanoi se localiza en España en las comunidades autónomas de Extremadura y Castilla-La Mancha y en Portugal, S. cordigera subsp. gentilii se puede encontrar en las zonas costeras del suroeste de Portugal, mientras que S. cordigera subsp. cordigera y S. parviflora se encuentran en la mayor parte de la Península Ibérica.

Palabras clave: Orchidaceae, Serapias perez-chiscanoi, Serapias cordigera subsp. gentilii, color de las flores, dimensiones de las flores, España, Portugal. 


\section{Introduction}

In 1976 Jose Luis Pérez Chiscano discovered deviant Serapias plants along the Guadiana river basin in Extremadura (Spain). After a twelve-year study, Pérez Chiscano (1988) described these plants as a new species, Serapias viridis Pérez Chiscano. Acedo (1990), however, found that the same name had been used for a Brazilian species by Vellozo (1825). To avoid confusion, the Spanish species was renamed S. perez-chiscanoi C. Acedo. Pérez Chiscano \& al. (1991) reported that only some eight populations of this species were known, all located in the Guadiana river basin in Extremadura. However, due to an increased interest in this species, many new populations were found in Extremadura during the past ten years (Venhuis \& al., 2006). Furthermore, the species was also found in Castilla-La Mancha (Venhuis \& al., 2006), and also in Portugal (Jansen, 1993). Observations on these recently found populations have increased our knowledge of the species. One new aspect is that plants with deviant reddish flower colours were found among the "normal" S. perez-chiscanoi individuals that have pale green flowers, or pale green flowers with a red venation. In this article, we describe the variation in flower colour in S. perez-chiscanoi and the differences and similarities in morphology and geographic distribution with other Serapias taxa.

\section{Material and methods}

In 2004 and 2010, we obtained morphological data for populations of Serapias cordigera subsp. cordigera L., S. cordigera subsp. gentilii C. Venhuis, P. Venhuis \& Kreutz, S. perez-chiscanoi and S. parviflora Parl. in Spain and Portugal. For both subspecies of S. cordigera, we measured 25 plants, from one population of subsp. cordigera in Extremadura, and likewise for subsp. gentilii in the Algarve. With S. perez-chiscanoi we measured 75 plants from three populations in Extremadura (Spain), and 5 plants from a population in mid-western Portugal. For S. parviflora, 50 plants were measured from two populations (Algarve and Extremadura) (Table 1). The latter data is not includ-

Table 1. Sampled populations of the studied Serapias taxa.

\begin{tabular}{|l|c|c|c|}
\hline Species & Location & Region & Country \\
\hline S. cordigera subsp. cordigera & Badajoz & Extremadura & Spain \\
S. cordigera subsp. gentilii & Cotifo & Algarve & Portugal \\
S. perez-chiscanoi & Badajoz & Extremadura & Spain \\
S. perez-chiscanoi & Aljucén & Extremadura & Spain \\
S. perez-chiscanoi & Trujillanos & Extremadura & Spain \\
S. perez-chiscanoi & Ereiras & Beira Litoral & Portugal \\
\hline
\end{tabular}

ed as this species is morphologically readily distinctive from the other taxa. According to the analyses by Venhuis \& al (2007), the dimensions of the epichile and hypochile are the most distinctive characters, and so in each population we measured the width and length of both the epichile and hypochile (Fig. 1).

\section{Results and discussion}

\section{Variation in flower colour}

Serapias perez-chiscanoi in Extremadura has a fairly uniform morphology and flower colour. The plants can be divided into two extremes, which present "green" or "red veined" variants. In the green variation (Fig. 2a, b), the leaves, stem, bracts, ovary, gynostegium, lamellae, flowers and veins are all pale green, with whitish hairs on the labellum. The lateral lobes of the flowers are yellowish and greenish. The "red veined" variation (Fig. 2c, d) is also greenish but with a red venation on the leaves, stem, bracts and ovary. It also has red veins and reddish hairs on the labellum and pinkish to reddish lateral lobes and lamellae. Intermediate colour variations occur very frequently (Venhuis \& al., 2004).

In Portugal, most of the known populations mainly comprise the "red veined" variation. A population of about 80 flowering plants in C Portugal contained in-

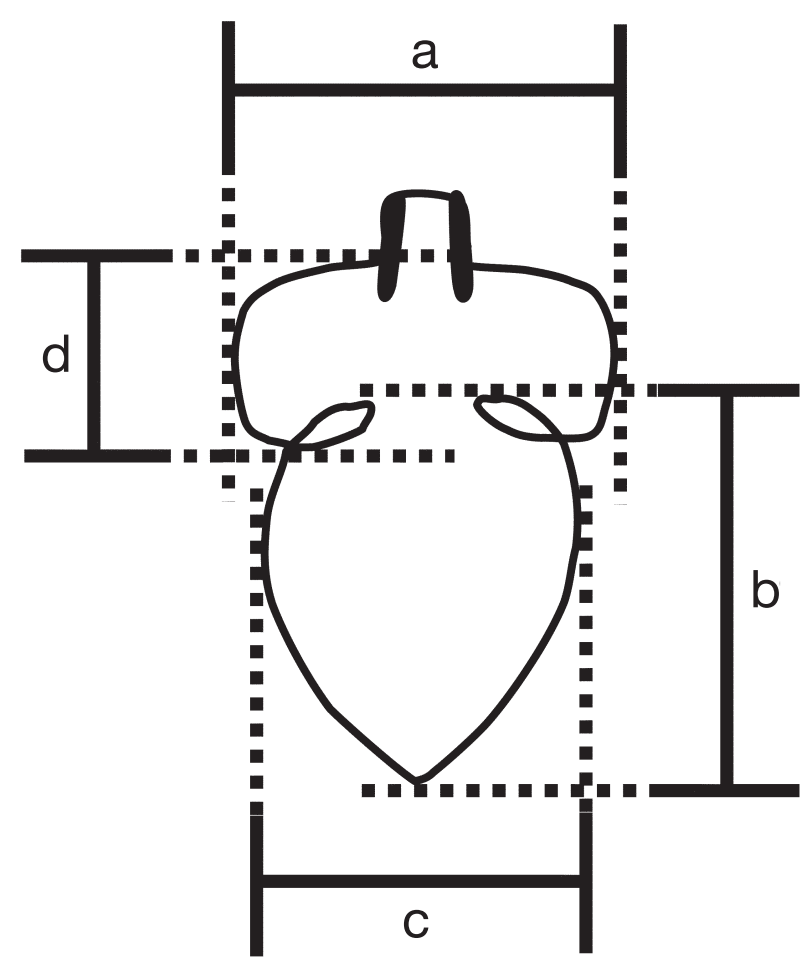

Fig. 1. Measured floral dimensions of the labellum: $\mathbf{a}$, hypochile width; b, epichile lenght; $\mathbf{c}$, epichile width; d, hypochile lenght. 

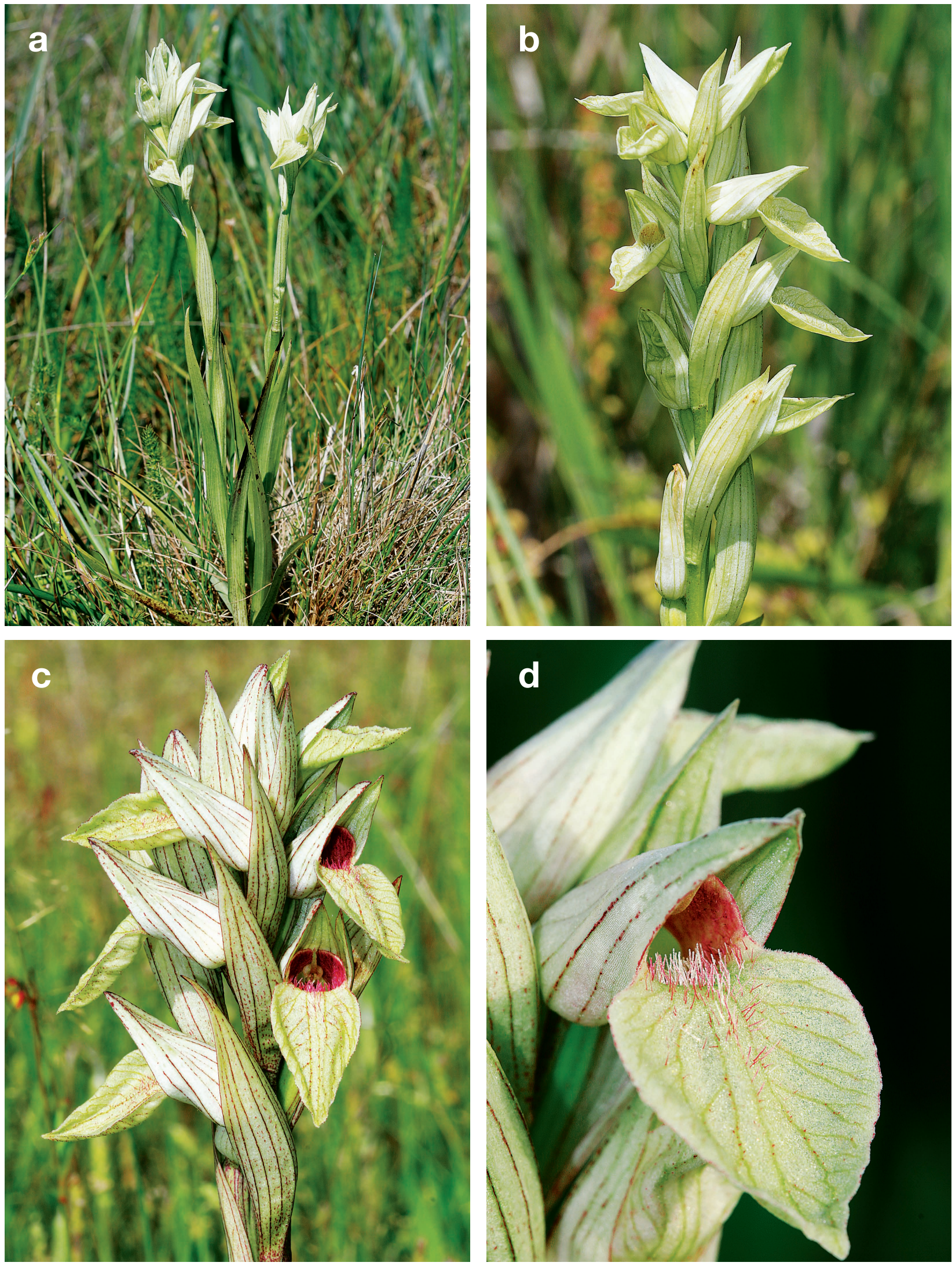

Fig. 2. a, Serapias perez-chiscanoi, Obando, Extremadura, Spain, 27-IV-2007; b, S. perez-chiscanoi, Trujillanos, Extremadura, Spain, 29-IV-2010; c, S. perez-chiscanoi, Vila Nova da Baronia, Baixo Alentejo, Portugal, 23-IV-2007; d, S. perez-chiscanoi, Alange, Extremadura, Spain, 30-IV-2010. All photographs: C. Venhuis. 

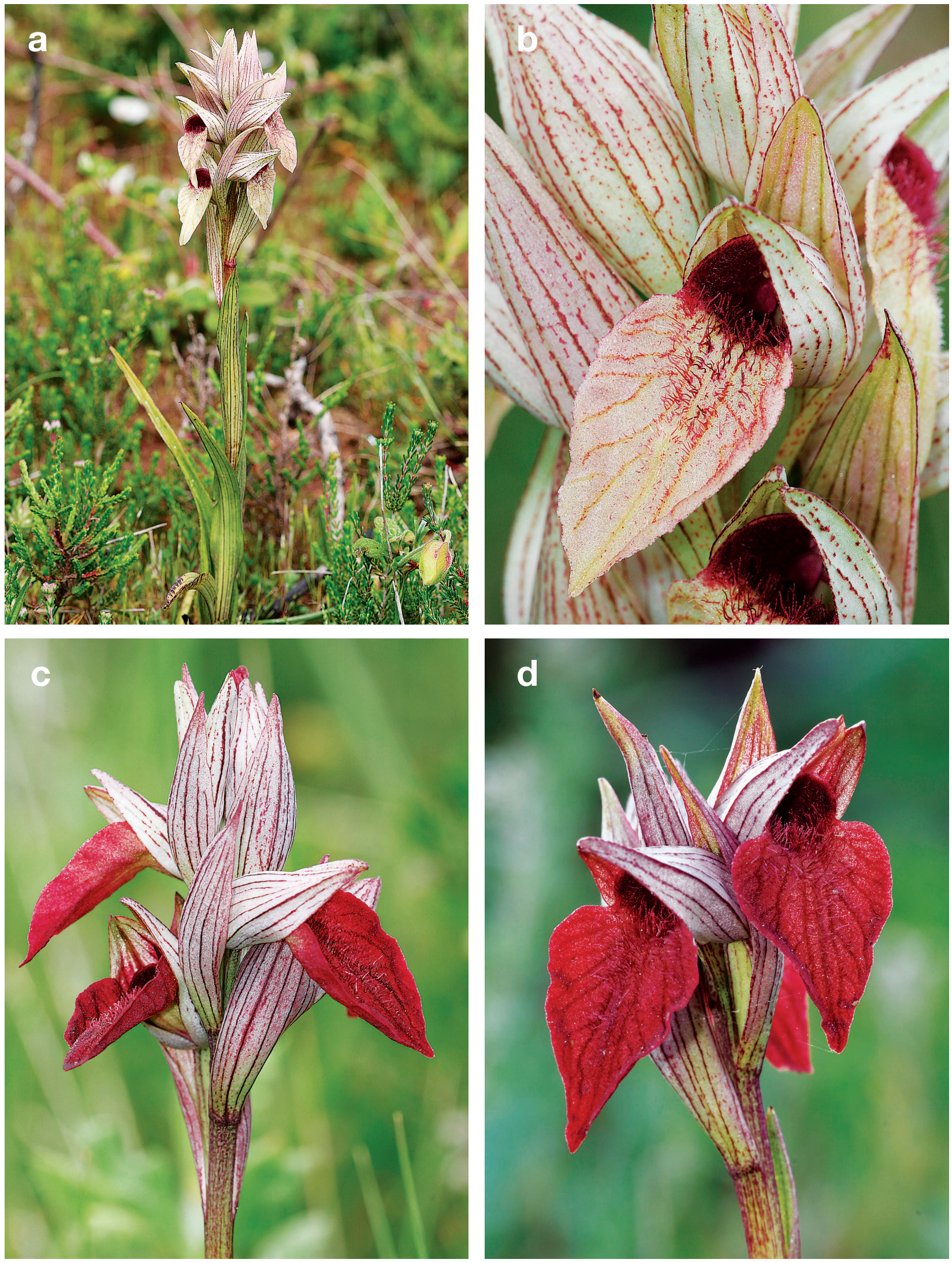

Fig. 3. a, Serapias perez-chiscanoi, Ereiras, Beira Litoral, Portugal, 1-V-2010; b, S. perez-chiscanoi, Ereiras, Beira Litoral, Portugal, 1-V-2010; c, S. perez-chiscanoi, Ereiras, Beira Litoral, Portugal, 1-V-2010; d, S. perez-chiscanoi, Ereiras, Beira Litoral, Portugal, 25-IV-2011. All photographs: C. Venhuis. 
dividuals with three flower colour variations. About ten plants were of the "green" variation, whilst some 50 plants were quite similar to the "red veined" variation, but differed from it by a bright red hypochile and lateral lobes, an epichile that was both greenish and pinkish, and the sepals, petals and bracts were also often slightly pinkish (Fig. 3a, b). The most deviant plants, however, about 20 individuals, had a bright red labellum (hypochile, lateral lobes and epichile), red petals and red veins on all plant parts. In addition, the bracts and sepals were pinkish (Fig. 3c, d).

\section{Hybridization}

Although hybridization cannot be excluded, the occurrence of hybrids is unlikely. The pollinia of S. perez-chiscanoi flowers disintegrate very rapidly onto their own stigmatic surface, often before the flowers open (Perez Chiscano \& al., 1991), and so the possibility that intact pollinia are transferred to another flower is limited. Moreover, S. perez-chiscanoi, is a diploid (Bernardos \& al., 2004), while S. lingua L., a species with which it is frequently sympatric, is tetraploid (D'Emerico \& al., 2000), so that the difference in ploidy level makes cross-fertility unlikely. In contrast, $S$. perez-chiscanoi very rarely co-occurs with the diploid $S$. cordigera, which makes hybridisation between these two species also highly unlikely. Nevertheless, hybrids between $S$. perez-chiscanoi and both $S$. lingua and S. cordigera have been reported. A hybrid between $S$. perez-chiscanoi and S. lingua was mentioned by Wallenwein \& Breier (1992) and was described subsequently as $S$. $\times$ venhuisia by Vázquez (2009). However, the photo in Wallenwein \& Breier (1992), is clearly of S. lingua; Vázquez did not provide any photographs. Furthermore, Venhuis \& al. (2004) and Vázquez (2009) suggested hybridization between $S$. perez-chiscanoi and S. cordigera. This putative hybrid was based on a plant near Aljucén (Venhuis \& al., 2004), from the same population as the photographs presented in this paper (Fig. 4a, b). The inflorescences of these very rare individuals contained salmon-pink and pink flowers, and it is noteworthy that flower colour varied within single plants. However, morphological measurements on the flowers of these 'hybrid' individuals revealed floral dimensions identical to $S$. perez-chiscanoi, and since the other putative parent, $S$. cordigera, did not occur in the vicinity, and no morphological character of any other Serapias species was present, we now conclude that these plants probably represent a pink-flowered form of $S$. perez-chiscanoi rather than a hybrid.

\section{Related species}

In the south-western part of the Iberian Peninsula about seven taxa of Serapias occur, which can be divided into two main groups based on their flower size: the $S$. vomeracea group and the $S$. parviflora group (Venhuis \& al., 2007). In this region, the $S$. vomeracea group includes $S$. cordigera subsp. cordigera, $S$. cordigera subsp. gentilii, $S$. perez-chiscanoi and $S$. occidentalis C. Venhuis \& P. Venhuis. The occurrence of S. vomeracea subsp. vomeracea in SW Spain and Portugal is uncertain (Venhuis \& al., 2007), and the taxonomic status of the new species, S. maria F.M. Váquez (Váquez, 2008), needs further study since the dimensions of morphological characters of this species overlap to a large extent with those of $S$. occidentalis. Further research on these taxa is necessary to determine their occurrence and taxonomic status respectively.

Taxa belonging to the $S$. parviflora group are S. parviflora, S. strictiflora Welwitsch ex Vega and $S$. lingua. Furthermore, two varieties of $S$. strictiflora are found in our region: var. elsae (P. Delforge) C. Venhuis \& P. Venhuis, and var. distenta Presser. In the field, $S$. perez-chiscanoi is easy to distinguish from most other co-occurring Serapias taxa on the basis of flower colour or floral dimensions. However, some taxa that occasionally have pale flowers, such as S. cordigera subsp. gentilii and S. parviflora, resemble S. perez-chiscanoi, and the differences between such individuals and $S$. perez-chiscanoi are clarified below.

\section{Differences with S. cordigera subsp. cordigera}

Serapias cordigera subsp. cordigera is presumed to be the parental species of $S$. perez-chiscanoi, and both taxa are similar morphologically (Venhuis \& al., 2007) and closely related according to molecular studies (Bellusci \& al., 2008). Nevertheless, S. cordigera subsp. cordigera, with its dark red to purple flowers with a large, heart-shaped epichile (Fig. 4c, d) is easily distinguished in the field from $S$. perez-chiscanoi. It can also be distinguished on the basis of three other features: 1) epichile position, 2) emergence of the lateral lobes and 3) inflorescence architecture. The epichile of $S$. cordigera subsp. cordigera is normally positioned parallel to the stem (i.e., pointing downwards), whereas the epichile of $S$. perez-chiscanoi is generally positioned at an angle of about 45-90 degrees to the stem (pointing more or less outwards). In S. cordigera subsp. cordigera, the lateral lobes protrude from the casco, whereas in $S$. perez-chiscanoi the lateral lobes remain hidden inside the hood. The flowers in S. cordigera subsp. cordigera are placed more or less opposite each other, whilst those of $S$. perezchiscanoi are positioned close together and in a spi- 

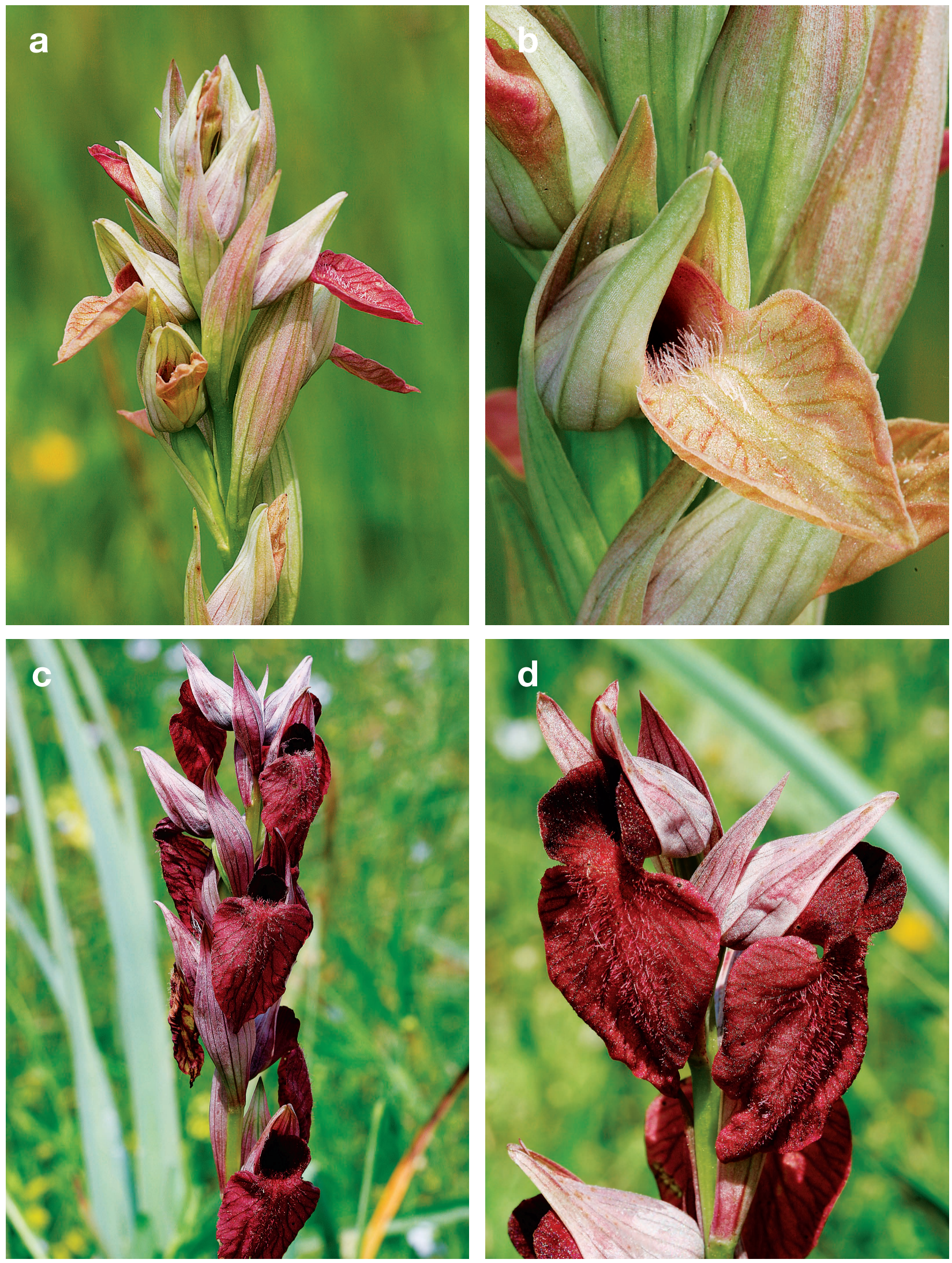

Fig. 4. a, Serapias perez-chiscanoi, Aljucén, Extremadura, Spain, 28-IV-2010; b, S. perez-chiscanoi, Aljucén, Extremadura, Spain, 28-IV-2010; c, S. cordigera subsp. cordigera, Badajoz, Extremadura, Spain, 30-IV-2010; d, S. cordigera subsp. cordigera, Badajoz, Extremadura, Spain, 30-IV-2010. All photographs: C. Venhuis. 

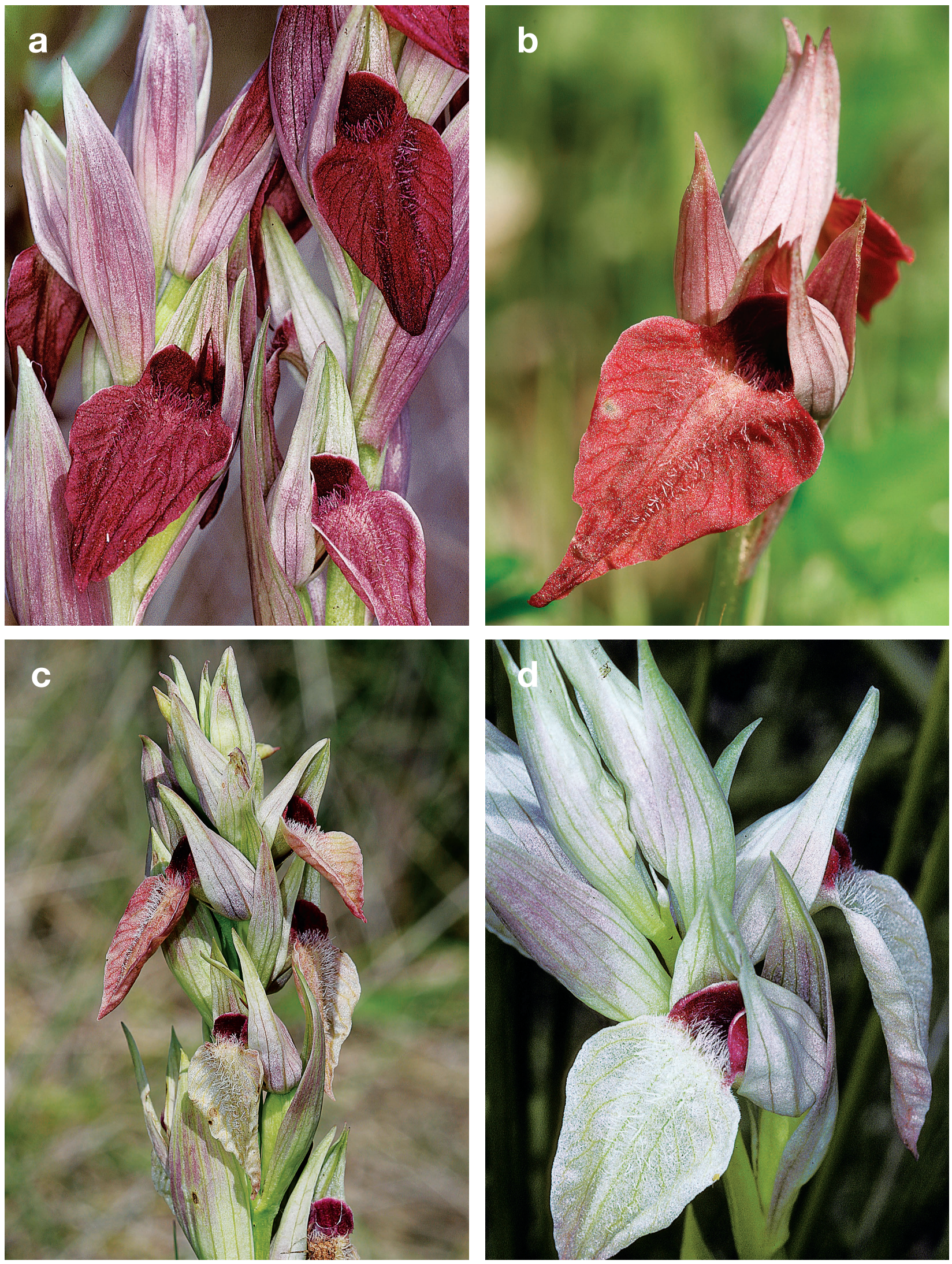

Fig. 5. a, Serapias cordigera subsp. gentilii, Barranco do Velho, Algarve, Portugal, 13-IV-1995; b, S. cordigera subsp. gentilii, Galaxos, Algarve, Portugal, 27-IV-2010; c, S. cordigera subsp. gentilii, Barranco do Velho, Algarve, Portugal, 26-IV-2010; d, S. cordigera subsp. gentilii, Barranco do Velho, Algarve, Portugal, 17-IV-1995. Photographs: a, d, D. Tyteca; b, c, C. Venhuis. 

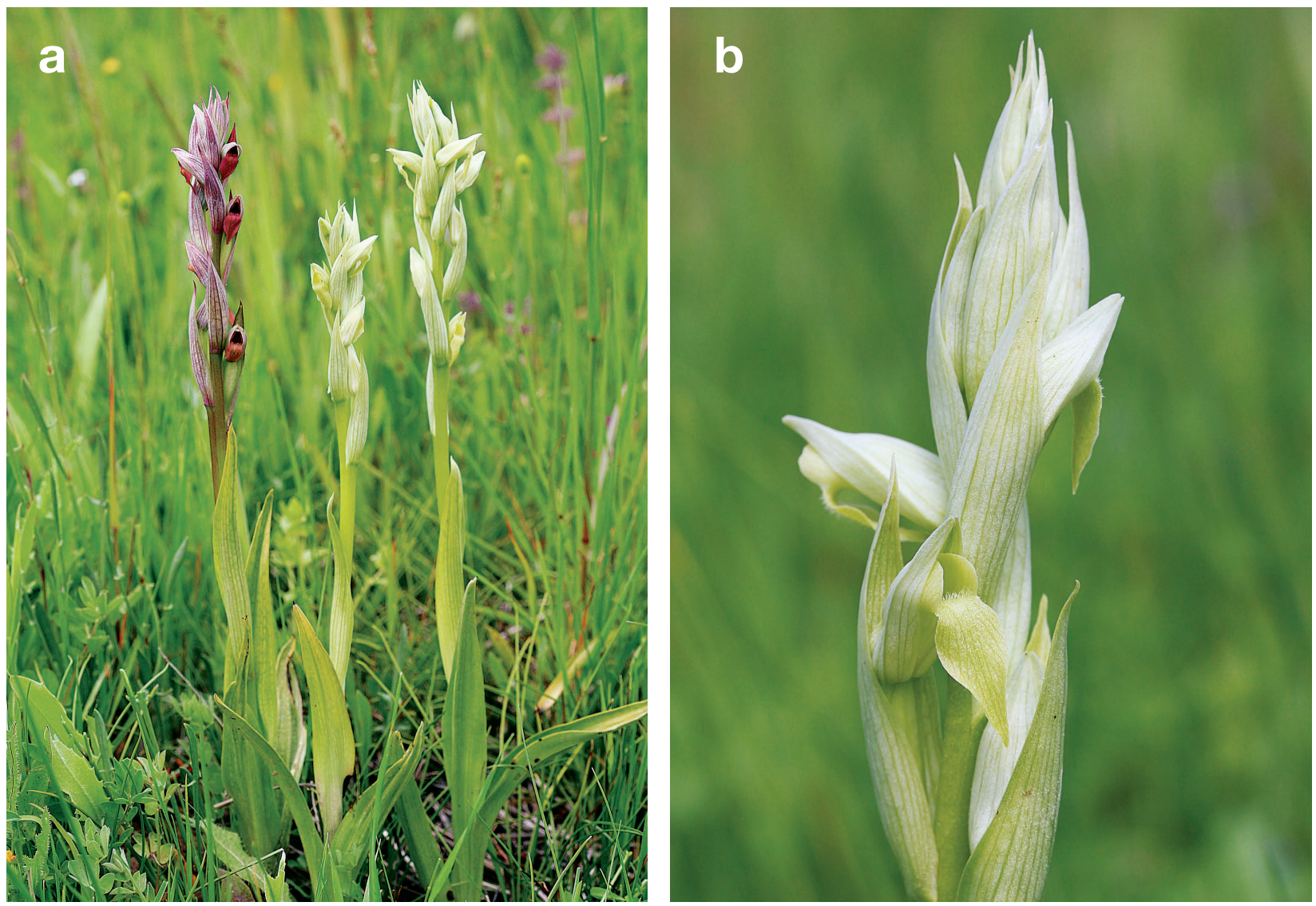

Fig. 6. a, Serapias parviflora, Aldeia dos Palheiros, Baixo Alentejo, Portugal, 23-IV-2007; b, S. parviflora, Aldeia dos Palheiros, Baixo Alentejo, Portugal, 23-IV-2007. Photographs: C. Venhuis.

ral, which gives the inflorescence a "twisted" appearance.

Although there is a small overlap in the epichile dimensions between $S$. cordigera subsp. cordigera and $S$. perez-chiscanoi: length (18)23-30(36) $\mathrm{mm}$ and (14)16-18(21) mm respectively, and width (13)1724(29) $\mathrm{mm}$ and (10)12-13(15) mm respectively, $S$. cordigera subsp. cordigera can be distinguished from $S$. perez-chiscanoi on the basis of the non-overlapping hypochile dimensions: length (10)11-14(17) $\mathrm{mm}$ and (6)7-8(9) mm respectively, and width (18)21-27(31) $\mathrm{mm}$ and (14)16-18(19) $\mathrm{mm}$ respectively (Fig. 7).

\section{Differences with S. cordigera subsp. gentili}

Serapias cordigera subsp. gentilii (Fig. 5 a-d) is sometimes difficult to differentiate from $S$. perez-chiscanoi because it occasionally has pale flowers that resemble the latter species. Most flowers of $S$. cordigera subsp. gentilii are red, but in many populations some plants with pale flowers occur, which vary from red with white edges (resembling $S$. nurrica Corrias), or completely pink, pink with yellow and pink with reddish veins, to yellowish, greenish or whitish (resembling $S$. perez-chiscanoi). In addition, several features that are present in $S$. cordigera subsp. cordigera are absent in $S$. cordigera subsp. gentilii and in S. perez-chiscanoi: the position of the epichile in the latter taxa generally points more or less outwards (although frequently downwards), and the inflorescence is, when there are many flowers, quite dense and spiralled and the edges of the epichile are often curled upwards. Furthermore, $S$. cordigera subsp. gentilii, like $S$. perez-chiscanoi, seems to be autonomously self-pollinating (Venhuis \& al., 2007). It differs from $S$. perez-chiscanoi, however, by lateral lobes that generally emerge from the hood in contrast to $S$. perez-chiscanoi in which the lateral lobes are always completely hidden inside it. Although the flowers of $S$. cordigera subsp. gentilii generally have a colour pattern quite different from $S$. perez-chiscanoi, some individuals have flowers with a greenish epichile that may superficially look similar. But in comparison with the "green" variation of $S$. perez-chiscanoi, these flowers have a red hypochile, while in comparison with the "red" variation of that taxon, they lack the reddish hairs on the labellum 

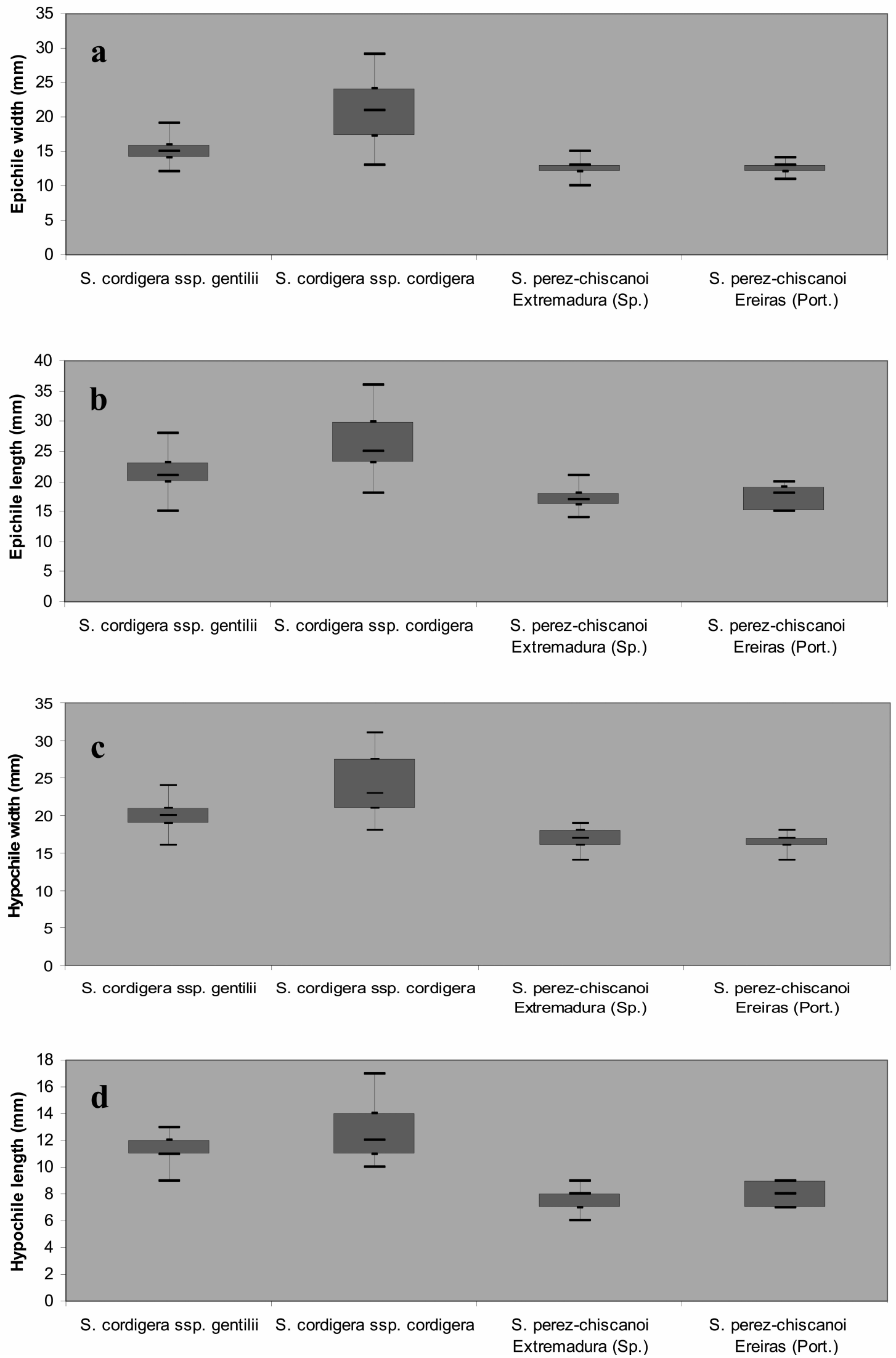

Fig. 7. Boxplots of Serapias cordigera subsp. gentilii, S. cordigera subsp. cordigera, S. perez-chiscanoi from Extremadura and S.perezchiscanoi from Portugal (Ereiras). Outliers and extremes were not removed. a, epichile width; b, epichile length; c, hypochile width; d, hypochile length. 
and the red venation on all plant parts. The red-flowered $S$. perez-chiscanoi, which until now was known from only one locality, is also very similar to the flowers of some plants of $S$. cordigera subsp. gentilii but differs from the latter subspecies by a striking red venation on all plant parts.

Most floral features are unhelpful to distinguish between these taxa, and the only character that separates $S$. cordigera subsp. gentilii from $S$. perez-chiscanoi is the length of the hypochile, which in $S$. cordigera subsp. gentilii is (9)11-12(13) $\mathrm{mm}$, and in S. perezchiscanoi is (6)7-8(9) mm (Fig. 7). All floral dimensions as well as the flower colour of $S$. cordigera subsp. gentilii are more or less intermediate between $S$. cordigera subsp. cordigera and S. perez-chiscanoi.

\section{Differences to S. parviflora}

Serapias parviflora is generally easily distinguished from $S$. perez-chiscanoi by its very small flowers. In the studied area, specimens of $S$. parviflora with pale pink and yellowish/greenish flowers (Figs. 6a, b) frequently occur, but these resemble $S$. perez-chiscanoi in colour only. Both taxa can be readily distinguished on the basis of three of the four labellum dimensions: Epichile length in S. parviflora ranges from (7)9-

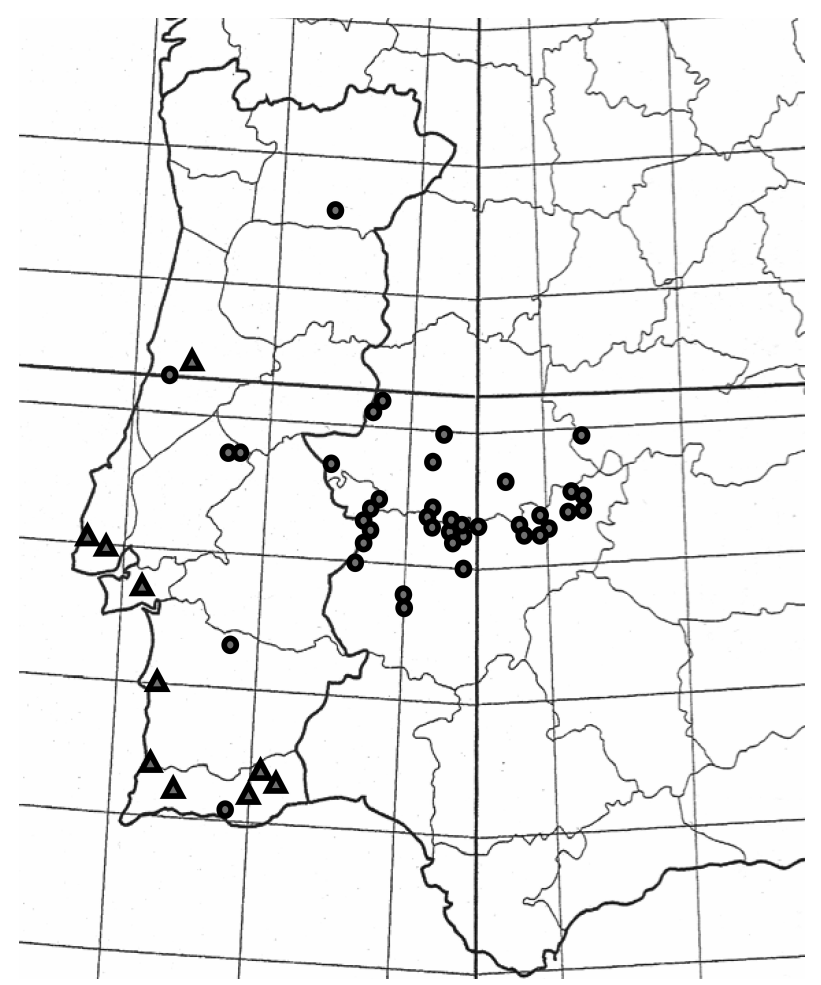

Fig. 8. Distribution map of Serapias perez-chiscanoi and S. cordigera subsp. gentilii. All known populations are presented, including populations that have already disappeared $(\mathbf{O}$ S. perezchiscanoi; $\boldsymbol{\Delta}$ S. cordigera subsp. gentilii).
11(12) $\mathrm{mm}$ and in S. perez-chiscanoi from (14)16$18(21) \mathrm{mm}$, the epichile width in $S$. parviflora falls between (2)4-6(6) $\mathrm{mm}$ and in S. perez-chiscanoi between (10)12-13(15) mm. Furthermore, S. parviflora differs from $S$. perez-chiscanoi in hypochile width (8)1011(13) $\mathrm{mm}$ and (14)16-18(19) $\mathrm{mm}$ respectively. Hypochile length does not differ: (5)7-8(9) $\mathrm{mm}$ and (6)78(9) $\mathrm{mm}$, respectively.

\section{Distribution}

Serapias perez-chiscanoi is a rare tongue-orchid, which was previously only known from the Guadiana river basin in Extremadura (Spain) (Pérez Chiscano, 1988; Pérez Chiscano \& al., 1991; Delforge, 2002). After a field study, Venhuis \& al. (2004) reported six new populations, and after intensive searches during the last five years by, amongst others, employees of the regional government of Extremadura, several new populations were found along the river basin of the Tajo and also south of the Guadiana river basin in Extremadura (Venhuis \& al., 2006), which increases the total number of populations known in Extremadura to around 30 (Fig. 8). Yet another population was found in Castilla-La Mancha (Venhuis \& al., 2006). In the Algarve (Portugal), Jansen (1993) found a population that disappeared soon after its discovery. And we have seen a population in the Baixo Alentejo province that was discovered by M. Pereira, and also four other populations that were discovered by either J. Moura, J. Pessoa and J. Monteiro, in the provinces of Beira Litoral and Ribatejo in the central part of Portugal and in the province of Trás-os-Montes e Alto Douro in northern Portugal (Fig. 8).

Serapias cordigera subsp. cordigera is found throughout the Iberian Peninsula, sometimes only locally but often abundantly. Serapias parviflora also occurs in the entire Iberian Peninsula, but is much more widespread and often abundant. Serapias cordigera subsp. gentilii is found predominantly along the coastal regions of the Algarve but also extends further north. The distribution map (Fig. 8) is based on populations seen by us, and photos, and also on literature, in which it was cited as a variety of $S$. cordigera.

\section{Identification key}

Here, we present a concise key for the identification of species from the large flowered $S$. vomeracea group in the SW Iberian Peninsula. It will be clear from this article that the identification of the different species is not too difficult, despite the considerable variation in flower morphology, flower colours and venation patterns. More research on the relationships 
between the morphological variation and the pollination ecology in $S$. perez-chiscanoi is underway.

\section{IDENTIFICATION KEY FOR THE SERAPIAS VOMERACEA GROUP}

IN THE SOUTHWESTERN PART OF THE IBERIAN PENINSULA

1. Ratio epichile width/hypochile length $=0.6-1.2$

\section{S. occidentalis}

1. Ratio epichile width/hypochile length $=1.3-2.1$

2. Hypochile length (6)7-8(9) mm S. perez-chiscanoi

2. Hypochile length (9)10-14(17) mm

3. Epichile broad and heart-shaped, purple, with no divergent edges; pollinia coherent ...... S. cordigera subsp. cordigera

3. Epichile slender, usually pale, often with divergent edges; pollinia friable

S. cordigera subsp. gentilii

\section{Acknowledgements}

We thank Marizia Pereira, Daniel Tyteca, Joaquim Pessoa, Jorge Moura and Karel Kreutz for their kind help with providing localities and/or photos of the studied species. Marisela Cornado Garcia is kindly acknowledged for translating the summary into Spanish.

\section{References}

Acedo, C. 1990. Serapias perez-chiscanoi, nom. nov. Anales del Jardin Botánico de Madrid 47(2): 510.

Bellusci, F., Pellegrino, G., Palermo, A.M. \& Musacchio, A. 2008. Phylogenetic relationships in the orchid genus Serapias L. based on noncoding regions of the chloroplast genome. Molecular Phylogenetics and Evolution 47: 986-991.

Bernardos, S., Tyteca, D. \& Amich, F. 2004. Cytotaxonomic study of some taxa of the subtribe Orchidinae (Orchidoideae, Orchidaceae) from the Iberian Peninsula. Israel Journal of Plant Sciences 52: 161-170.

Delforge P. 2002. Guía de las Orquídeas de España y Europa. Lynx Ediciones, Barcelona, Spain.
D’Emerico, S., Pignone, D. \& Scrugli, A. 2000. Giemsa C-banded karyotypes in Serapias L. (Orchidaceae). Botanical Journal of the Linnean Society 133: 485-492.

Jansen H. 1993. Serapias viridis Pérez Chiscano in Portugal! Mitteilungsblatts des Arbeitskreises Heimische Orchideen BadenWürttemberg 10: 50-53.

Pérez Chiscano, J.L. 1988. Nueva especie de Serapias L. en Extremadura (España). Monografias del Instituto Pirenaico de Ecologia, Homenaje a Pedro Montserrat, Jaca y Huesca: 305-309.

Pérez Chiscano, J.L., J.R. Gil Llano \& F. Duran Oliva. 1991. Orquideas de Extremadura. Fonda Natural, Madrid.

Tyteca, D. 1997. The orchid flora of Portugal. Journal Europäischer Orchideen 29(2/3): 185-581.

Vázquez Pardo, F.M. 2008. Annotations to the Orchidaceae of Extremadura (SW Spain). Journal Europäischer Orchideen 40(4): 699-725.

Vázquez Pardo, F.M. 2009. Revisión de la familia Orchidaceae en Extremadura (España). Folia Botanica Extremadurensis 3: 5-368

Vellozo, J.M. da C. 1825. Florae fluminensis. Senefelder, Rio de Janeiro, Brasil.

Venhuis, C., Oostermeijer, J.G.B. \& Tonk, J.Th.P. 2004 Conservation biology of Serapias perez-chiscanoi Acedo in the Guadiana river basin in Extremadura (Spain). Eurorchis 16: 49-63.

Venhuis, C., Oostermeijer, J.G.B. \& Cornado Garcia, M. 2006. Serapias perez-chiscanoi: legal protection and distribution. Eurorchis 18: 88-91.

Venhuis, C., Venhuis, P., Oostermeijer, J.G.B. \& van Tienderen, P.H. 2007. Morphological systematics of Serapias L. (Orchidaceae) in Southwest Europe. Plant Systematics and Evolution 265: 165-177.

Wallenwein, F. \& Breier, W. 1992. Bemerkungen zu einigen Arten der Gattung Serapias L. aus Spanien. Mitteilungsblatts des Arbeitskreises Heimische Orchideen Baden-Württemberg 24(1): 115-121.

Associate Editor: L. Sáez Received: 27-IX-2010

Accepted: 7-II-2011 